\title{
GESTÃO ESCOLAR: REFLEXÕES E IMPORTÂNCIA
}

Adriana Croti, Elisangela Aparecida Bulla Ikeshoji, Adriano Rodrigues Ruiz

Universidade do Oeste Paulista - UNOESTE. Mestrado em Educação, Presidente Prudente - SP. E-mail: adrianacroti@hotmail.com.br

\section{RESUMO}

A gestão escolar é tema recorrente do debate político educacional e seu conceito apresenta diversas lacunas. Entre outras, uma refere-se ao fato que, nas escolas, as relações entre docentes e alunos, assim como de todos os envolvidos dentro desse contexto devem convergir para atingir um propósito pedagógico, a educação. A partir de 1990 o enfoque para a educação ganha um novo direcionamento. As novas exigências que a economia globalizada começa a desvelar induz a interferência do setor produtivo ao setor educacional. E assim, em virtude destas mudanças socioeconômicas, é que a educação passou a integrar a agenda política como meio de aumento da produtividade e cidadania globalizada. A partir da leitura de pesquisadores sobre a temática, este artigo aborda aspectos sobre o papel da gestão escolar, sua evolução no contexto histórico e busca a partir de uma análise crítica apresentar um direcionamento teórico/prático.

Palavras-chave: Gestão, Cultura, Escola, Educação, Formação.

\section{SCHOOL MANAGEMENT: REFLECTIONS AND IMPORTANCE}

\begin{abstract}
The school management is a recurring theme of educational political debate and its concept has several shortcomings. Among others, one refers to the fact that, in schools, relationships between teachers and students, as well as everyone involved in this context must converge to achieve a pedagogical purpose, the education. Since 1990 the focus for education gets a new direction. The new requirements that the global economy starts to unravel induces interference from the productive sector to the education sector. And so, by virtue of these socioeconomic changes, is that education became part of the political agenda as a means of increasing productivity and global citizenship. From the reading of researchers on the topic, this article focuses on the role of school management, its evolution in historical context and search from a critical analysis present a theoretical / practical direction.
\end{abstract}

Keywords: Management, Culture, School, Education, Training. 


\section{INTRODUÇÃO}

A concepção de gestão escolar apresenta diversas lacunas conceituais. Entre outros aspectos, esta lacuna refere-se ao fato que, nas escolas, as relações entre docentes e alunos, assim como de todos os envolvidos dentro desse contexto devem convergir para atingir um propósito pedagógico: a educação. Por outro lado, nas organizações, as relações entre empregado e empregador decorrem da compra e venda da força do trabalho com o objetivo de, na grande maioria dos casos, a venda de bens, serviços ou informações. A diferença está na riqueza proporcionada pela escola, o "se fazer humano na ação pedagógica" (WELLEN; WELLEN 2010).

A gestão escolar é tema recorrente do debate político educacional. Durante a ditadura militar, com as estruturas administrativas centralizadas e burocratizadas, os diretores das escolas obedeciam às regras impostas, nesse momento as reivindicações dos educadores tratavam de obter a autonomia escolar, sendo esta vinculada à necessidade de alternativas curriculares e didáticas no combate à evasão e repetência que ocorria (KRAWCZYK, 1999).

Relata ainda, a autora, que nas décadas 1950 e 1960 a ideia de autonomia escolar e liberdade dos educadores tinham o intuito de rebater a vigência das ações administrativas e intervenções políticas com projetos alheios à realidade escolar. O silenciar das reinvindicações na década de 1970 revela o ápice do processo de centralização administrativa. A gestão escolar volta à cena do debate político na década de 1980, com um novo contexto - a reforma do Estado. Tais reformas eram desejáveis uma vez que carregavam no seu bojo a equidade, justiça social, redução de clientelismo e fortalecimento da democracia, desta forma a descentralização retoma sua força (KRAWCZYK, 1999).

Entender estas contradições sociais é essencial, pois desta maneira o gestor tem condições de fazer da escola um contexto onde não se reproduza os reflexos das estruturas da sociedade capitalista, mas que se reflitam estas interferências de forma consciente, contribuindo para uma ação pedagógica mais abrangente e consequentemente para uma formação emancipadora.

Todavia, ainda segundo Krawczyk (1999), na década de 1990 o enfoque para a educação ganha um novo direcionamento. As novas exigências que a economia globalizada começa a desvelar induz a interferência do setor produtivo ao setor educacional. $E$ assim, dadas estas mudanças socioeconômicas, é que a educação passou a integrar a agenda política como meio de aumento da produtividade e cidadania globalizada. 


\section{GESTÃO: REFLEXÕES E CRÍTICAS}

Deixando os meandros do contexto sócio-politico-econômico e com vistas ao enfoque de Teoria Administrativa, podemos relacionar que nas décadas de 1960 e 1970 o referencial teórico no pressuposto da gestão escolar estava enraizado na Teoria Geral da Administração (TGA), com um esforço em se delimitar a administração escolar como área específica de estudo. (ABDIAN, OLIVEIRA E HOJAS, 2010). Contudo, em meados da década de 1980 surgem críticas às ideias anteriores e, a partir deste período, o enfoque recai para o estudo do trabalho coletivo, e a participação da comunidade escolar na gestão. Assim, os princípios da gestão democrática ganham corpo na teoria e nos espaços escolares (RUSSO, 2004).

Para Rangel (2009) o que houve foi um neofuncionalismo, ou seja, a aplicação radical das teorias administrativas na escola, sem considerar os objetivos e o papel da escola, suas particularidades. Não se observou o que Cohn (1998, p. 58) aborda com maestria,

a partir do momento em que cabe ao sistema responder a exigências funcionais, e essas exigências derivam de relações com um ambiente marcado pela contingência (incapaz, portanto, de orientar a constituição mais adequada do sistema) este enfrenta uma tarefa nova: a de criar por sua conta os seus próprios elementos, realizar operações autoconstitutivas [...].

A organização do sistema escolar, tendo como norte a gestão democrática pede que os objetivos educacionais sejam bem definidos, com representatividade das necessidades da comunidade e considere as especificidades do projeto pedagógico (LIBÂNEO et al., 2012).

Apesar da conquista da gestão democrática constar na forma de lei, fundamentada na Lei de Diretrizes e Bases no. 9394/96 - LDB, e acompanhar a tendência da hegemonia mundial com destaque para três aspectos: descentralização administrativa, participação da sociedade civil e autonomia crescente dos sistemas e das escolas públicas (BRASIL, 1996) muitos impasses na prática dificultam a sua aplicação.

Para Senge (2005) enfrentar estas limitações é fator essencial para produzir mudanças, pois isto não pode impedir a escola de exercer seu papel fundamental, a educação. É preciso superar, as divisões e segmentações existentes na escola, assim como as oferecidas pelas políticas públicas.

Para parte das teorias organizacionais aplicadas à escola parece haver uma compreensão de que a gestão escolar é conjunto de aspectos de natureza técnica, com campos de conhecimentos delimitados: a administração e a pedagogia. Esses pensadores compreendem, à luz da teoria clássica da administração ou das teorias das escolas que a substituíram (das teorias da burocracia), a gestão escolar como 
um fenômeno administrativo no qual os recursos são utilizados por meio das técnicas disponíveis para o alcance dos objetivos e fins da organização, portanto, sugerindo a ideia de uma forma/técnica ótima de se conduzir tal fenômeno (SOUZA, 2012, p. 161-162).

É importante observar a dualidade colocada por Paro (1988) apud Wellen; Wellen (2010), segundo a autora na maioria das obras escritas sobre gestão escolar ou se voltava para a defesa e a legitimação dos princípios da administração capitalista, encarando-os como possuidores de caráter universal, ou, por enxergar na gestão escolar apenas práticas burocráticas e autoritárias, negava e descartava qualquer possibilidade de avanço ou mudança neste contexto.

Para se entender a realidade da gestão escolar é necessário observar que a escola não existe num modelo ideal, mas apresenta-se como resultado das vontades humanas e recebe grande influência da sociedade que a organiza para produzir condições materiais de sobrevivência (WELLEN; WELLEN 2010). Lembrando Karl Marx (MARX; ENGELS, 2007) antes do ser humano realizar qualquer pensar, seja no campo da política, arte, ou ciência o ser humano precisa se preocupar em comer, beber, vestir e abrigar-se.

Com base nesta perspectiva, e com a mudança de visão sócio-político e econômica, já apontadas por Krawczyk (1999), devido ao processo de globalização, o objetivo da educação escolar pode reproduzir apenas os anseios do sistema de produção vigente, no caso do Brasil, o capitalismo. Porém, se os objetivos da instituição escolar convergem para além deste, pode contemplar a aprendizagem escolar, como a formação da cidadania e, se todas as ações da gestão escolar no seu bojo propiciam as condições para alcançar os objetivos expostos, torna-se possível uma educação que se volta mais a uma formação do ser humano (LIBÂNEO et al., 2012).

Ainda, é importante ressaltar que a gestão escolar não constitui um conjunto de técnicas e ferramenta formadas em abstrato, mas expressam um resultado histórico das tendências decorrentes do desenvolvimento da sociedade (WELLEN; WELLEN, 2010).

Os erros e ilusões fazem parte da mente humana (MORIN, 2000), se considerar que ao reconstruir algo visto, seja pela linguagem ou pensamento pode ocorrer uma tradução ilusória. Complementa Marx (2007) sobre a ideia falsa que o homem tem de si, da vida e do mundo. Estendese assim, à questão da gestão escolar, que não é neutra, mas deve compreender sua intencionalidade. E por isso, o gestor precisa pressupor que seu papel está em planejar, coordenar, controlar (CHIAVENATO, 2003), assim como atuar sobre valores, crenças, sentimentos, emoções, de 
maneira tal que provoque reações dos docentes para o enfrentamento dos desafios escolar, sendo estas importantes e favorecedoras para que objetivos educacionais sejam alcançados (LÜCK, 2011).

O gestor necessita desenvolver seu trabalho e compreender o efeito deste, tendo por base o processo da gestão. Assim como o docente ao entender o processo de gestão participa de forma mais ativa e efetiva nas ações da escola (LÜCK, 2011).

Sendo assim, antes de avançar em alguns aspectos da gestão, enunciar os termos Administração e Gestão parece ser bastante oportuno. Administração é o processo de planejar, organizar, dirigir e controlar pessoas para alcançar objetivos organizacionais (CHIAVENATO, 2003). Volta-se mais como uma função administrativa, refere-se aos princípios de organizar, estruturar e controlar os recursos disponíveis (LIBÂNEO et al., 2012). A gestão implica atuar sobre as questões que envolvem as ações das pessoas, identifica-se como um empreendimento que visa à promoção humana, para atingir os objetivos organizacionais (LÜCK, 2011; LIBÂNEO et al., 2012). No entanto, em ambos os casos, Libâneo et al. (2012) nomeiam que estas organizações são unidades sociais, destinam-se a alcançar determinados objetivos, embora cada qual com objetivos específicos e distintos.

Nas organizações empresariais, enquanto unidades sociais, a função administrativa se sobressai, entende-se aqui que as pessoas são tratadas como recursos, assim como o dinheiro, a matéria-prima, o que as distingue das organizações escolares, unidades sociais voltadas à busca essencialmente da promoção e formação humana. Nesta última, as funções administrativas também estão presentes, sendo de total importância, no entanto não se constituem como o elemento essencial.

Entende-se assim que a gestão que emana no ambiente escolar deve ser norteada para a educação. Tendo a escola como essencial objetivo a educação, uma vez que favorece a formação do ser humano. Nela se sobressai a interação entre as pessoas, cujo desenvolvimento das potencialidades físicas, cognitivas, afetivas e atitudinais ocorre via o processo de ensinoaprendizagem (LIBÂNEO et al., 2012). Processo esse, o qual o gestor precisa compreender para intervir, conforme menciona Lück (2011, p. 131):

[...] quando o dirigente escolar atua sobre o modo de ser e de fazer da organização educacional, está efetivamente promovendo gestão escolar, isto é, está mobilizando esforços, canalizando energia e competências, articulando vontades e promovendo a integração de processos voltados para a efetivação de ações necessárias à 
realização dos objetivos educacionais, os quais demandam a atuação da escola como um todo de forma consistente, coerente e articulada.

O gestor tem o papel fundamental de lidar com as competências, os valores, as crenças de todos os envolvidos nas ações da escola, com o intuito de convergir os esforços para atingir os objetivos que devem ser comum, a educação.

Entretanto, nas organizações empresariais, a preocupação se volta essencialmente ao processo produtivo que reflete e acaba por interferir no desenvolvimento da sociedade como um todo. Cabe à escola conhecer esse modo de produção e como ele se produz na sociedade, assim como desvelar de forma crítica para que se compreenda que as bases do sistema de produção é que reforça que o mundo precisa funcionar desta maneira (WELLEN; WELLEN, 2010).

Portanto, ainda segundo Wellen; Wellen (2010, p. 165), o ser humano "pode realmente não relacionar diretamente as negatividades do seu trabalho e de vida às imposições do seu patrão ou do sistema capitalista, mas essas determinações não passam incólumes na consciência do trabalhador". Se assim o é, melhor e mais favorável, a escola pode e deve contribuir para este desvelar.

Sendo assim, é importante reconhecer e compreender as necessidades dos trabalhadores no mundo do trabalho e os permitir perceber as ligações que a formação educacional oferecida pela escola pode proporcionar ao levar a repensar este contexto da relação com o trabalho, no sistema de produção capitalista e transformar a realidade social (PISTRAK, 2002; LIBÂNEO et al., 2012).

Entender estas contradições sociais é essencial, pois desta maneira o gestor tem condições para fazer da escola um contexto onde não se reproduza os reflexos das estruturas da sociedade capitalista, mas que se reflitam estas interferências conscientes, contribuindo para uma ação pedagógica mais abrangente e consequentemente para uma formação emancipadora.

Segundo Libâneo et al. (2012) estudos demonstram a indicação de algumas características organizacionais que podem ser utilizadas no contexto escolar. Porém, cabe a ressalva, é importante considerar que as escolas não são iguais e por isso nem sempre é possível generalizar, mas quando bem compreendidas e geridas, determinadas características, podem interferir no modo de ser e de se fazer da escola. Logo, as características organizacionais quando compreendidas e adequadamente adaptadas, pelo gestor brotam efeitos positivos, acolhe a proposta de Cohn (1998). Quando o gestor consegue implementá-las para promover e guiar as ações dos docentes, com vistas a prepará-los melhor em sua atividades para assim ter clareza quanto ao seu complexo papel na docência refletindo 
na preparação de seus objetivos em sala de aula e conteúdos; projeto pedagógico bem definido, onde reside o consenso mínimo entre direção e corpo docente; bom clima de trabalho; papel significativo da direção e coordenação pedagógica; equipe disposta a inovar sem perder a identidade, atingem melhores resultados educacionais.

\section{ALGUMAS CONSIDERAÇÕES}

Entender a gestão escolar passa por compreender que "o fenômeno educativo é gerido e gestado por todos os profissionais da educação, que se encontram trabalhando em uma unidade educacional" (RANGEL, 2009, p. 26). Sendo importante cada um conhecer o seu papel e a relevância que a formação continuada propicia ao gestor, docente e demais pessoas envolvidas ao utilizar-se da ciência para acrescer em conhecimento para sua própria formação e a do coletivo, quando destacada por Fraga (2009, p, 167),

com essa possibilidade de mostração do fenômeno é que o agente precisa estar permanentemente sintonizado na gestão, se é que ele pretende compreender os problemas como eles realmente são, e não substituí-los por suas representações. Esse cuidado exige convívio intenso, cotidiano, em busca do em comum.

Por isto pensar que a qualidade social e pedagógica pode ser alcançada quando unidas a gestão organizacional e administrativa (RANGEL, 2009). Complementa Libâneo $(2004$, p. 10)

Uma escola bem organizada e bem gerida é aquela que cria condições pedagógicodidáticas, organizacionais e operacionais que propiciam o bom desempenho dos professores em sala de aula, de modo que todos os seus alunos sejam bemsucedidos na aprendizagem escolar.

\section{REFERÊNCIAS}

ABDIAN, G. Z.; OLIVEIRA, M. E. N.; HOJAS, V. F. Formação, função e formas de provimento do cargo de administrador escolar: questões em análise. In: SEMINÁRIO NACIONAL DE ADMINISTRAÇÃO EDUCACIONAL. Reforma do Estado e Políticas Educacionais do Brasil: o público e o privado em questão. Encontro Estadual da Associação Nacional de Política e Administração da Educação - ANPAE, 2010, Teresina, PI. Anais...Teresina: NEPES/UESPI; NUPPEGE/UFPI; ANPAE; CAPES; FAPESP, 2010. 1 CD Rom.

BRASIL. Lei Darci Ribeiro (1996). LDB: Lei de Diretrizes e Bases da Educação Nacional. Lei no 9394, de 20 de dezembro de 1996. Estabelece as diretrizes e bases da educação nacional. 4ed. Brasília: Câmara do Deputados, Coordenação de Publicações, 2007. 
CHIAVENATO, I. Introdução à teoria geral da administração: uma visão abrangente da moderna administração das organizações. Rio de Janeiro: Elsevier, 2003.

COHN, G. (1998). As diferenças finas: de Simmel a Luhmann. Revista Brasileira de Ciências Sociais, 13(38), 53-62. http://dx.doi.org/10.1590/S0102-69091998000300003

FRAGA, V. F. Gestão pela formação humana: uma abordagem fenomenológica. Barueri, 2009.

KRAWCZYK, N. A gestão escolar: um campo minado... Análise das propostas de 11 municípios brasileiros. Educ. Soc., Campinas, v. 20, n. 67, Aug. 1999. Available from $<$ http://www.scielo.br/scielo.php?script=sci_arttext\&pid=S010173301999000200005\&lng=en\&nrm=iso>. access on 10 Aug. 2014. http://dx.doi.org/10.1590/S0101$\underline{73301999000200005}$

LIBÂNEO, J. C; OLIVEIRA, J. F.; TOSCHI, M. S. Educação escolar: políticas, estruturas e organização. São Paulo: Cortez, 2012.

. Organização e gestão da escola: teoria e prática. Goiânia: Alternativa, 2004.

LÜCK, H. Gestão da cultura e do clima organizacional da escola. 2. ed. Petrópolis, RJ: Vozes, 2011. Vol. V, série cadernos de gestão.

MARX, K.; ENGELS, F. A ideologia alemã. São Paulo: Martins Fontes, 2007. p. 3-4.

MORIN, E. Os setes saberes necessários à educação do futuro. 2. ed. São Paulo: Cortez, 2000.

PISTRAK, M. Fundamentos da escola do trabalho. São Paulo: Expressão Popular, 2002.

RANGEL, M. (org). Supervisão e gestão na escola: conceitos e práticas de mediação. Campinas: Papirus, 2009.

RUSSO, M. H. Escola e paradigmas de gestão. Eccos - Revista Científica, São Paulo, v.6, n.1, p. 25-42, 2004.

SENGE, P. Escolas que aprendem: um guia da quinta disciplina para educadores, pais e todos que se interessam pela educação. Porto Alegre: Artmed, 2005.

SOUZA, Ângelo Ricardo De. A natureza política da gestão escolar e as disputas pelo poder na escola. Rev. Bras. Educ., Rio de Janeiro, v. 17, n. 49, Apr. 2012 . Available from $<$ http://www.scielo.br/scielo.php?script=sci_arttext\&pid=S1413-

24782012000100009\&lng=en\&nrm=iso>. access on 09 Aug. 2014. http://dx.doi.org/10.1590/S1413$\underline{24782012000100009}$

WELLEN, H.; WELLEN, H. Gestão organizacional e escolar: uma análise crítica. Curitiba: Ibpex, 2010. 